\title{
Bringing evidence to the point of care
}

Evidence-based medicine calls for the integration of our clinical expertise and our patients' values with the best available extemal evidence (1). To accomplish this, we must translate our information needs into answerable questions and then seek the best information with which to answer them (2). Critics of evidencebased medicine have appropriately suggested that its practice may require tine and resources unavailable to busy clinim. cians (3). Davidoff and colleagues suggested that a general physician would need to read 17 articles each day to keep up with the current rnedical literature (4). Clinicians have little time to set aside for keeping up-to-date or for reading in be-" tween seeing patients, and sels-reported weekly reading times reflect this: Consultants report reading from 30 to 45 mimutes each week, while house officers report from 0 to 20 minutes (5). Further, some dinicians don't have quick access to the evidence and may have to travel several floors, blocks, or even miles to visit their local library to find it.

Proponents of evidence-based mecícine are meeting these challenges in various ways. The development of the Cochrane Library, along with the growing number of evidence-based journals of quality-and relevance-filtered secondary publications (e.g., Evidence-Based Mediche and Evidence-based Health Policy and Management) and the creation of "best evidence" sections in a number of established journals (e.g., foumal of Pediatric and foumal of Family Practice), have resulted in better accessibility of high-quality evidence for clinicians. The Cochrane Library is available on CD and on the Internet for lectronic searching.

Family physicians have expressed great interest in having patient-education materials, drug information, and overviews of treatment recommendations available on computers (6). Housestaff have stated they like having access to high-quality evidence at the bedside but would prefer to have it available for use within 30 seconds (7). These sur- veys suggest that we need to find ways of speedily delivering high-quality evidence to the point of care.

Several groups are working to find ways to provide quick access to the endence. We recently used an evidence cart (7) that included a notebook computer containing Best Evidence (a CD containing $A C P$ Foumal Chub and Evidence-Based Medicine), the Cochrane Library, MEDLINE, and a collection of 149 one page summaries of critically appraised topics (CATs) created in response to dinical questions posed by previous members of our clinical teams (8). The cart (housed in a seminar room between our wards) was used on our clinical and teaching rounds and whenever a member of the clinical team posed a question. The resources that could be accessed the fastest (we could find specific 1-page summaries in under 12 seconds) wete used most frequently and most often resulted in a successful search. Our speed of access to evidence using these resources was probably more rapid because these resources were developed by our clinical teams for this purpose and, therefore, their contents were well known to us. However, such customised information is being developed in a number of settings. We could access specific entries in Best Evidence in 23 seconds (about the apper limit of time we were willing to devote to searching during our rounds) and found that we could answer 16 questions using this resource on the ward in the time it took us to answer just one using the library ( 4 floors away). MEDLINE was successful at answering our questions ( $59 \%$ of the time) but was so slow (mean time for a successful search was 90 seconds) that most searches were completed outside of rounds. Similarly, the evidence in the Cochrane Library was superb, but it took too long to find during rounds. The evidence found altered the clinical approach of at least 1 team member $48 \%$ of the time. During the month after removal of the cart, the team iden- tified several occasions when they needed evidence but only carried out searches on $12 \%$ of these.

This experience convinced us that our housestaff (and patients) would benefit from rapid access to high-quality evidence. Because our team felt that the "worst thing" about the evidence cart was its bulk, we abandoned the cart and issued every team member a hand-held (Toshiba or Epson) computer (8). These were radio-linked to our hospital's network, which provided CATs; Best Evw dence; a lab handbook; the Cochrane Libraty; MEDLINE; and the lab resuits for individual patients, which were linked to relevant CATs. During this 2-week pilot, our housestaff searched an average of 10 times per day. As before, the most frequent, quickest, and most successful searches were for CATs, and the Cochrane Library was used least frequently and with the least success. Because the current generation of handheld computers are too slow for routine use, we are turning our attention to evaluating radio linked laptops that can be carried on the chart rack and taken to the bedside.

Other groups have tested similar ap proaches for bringing rapid evidence to the point of care. Helwig and colleagues (9) are providing Newton MP2000 palm-top computers containing some evidence-based materials to medical students completing an ambulatory medicine rotation. Students were able to find answers to clinical questions within 30 seconds. Further analysis of this project is ongoing. Ebell and colleagues $(10,11)$ have developed an application for Newton hand-held computers that provides critical appraisals froril the Foumal of Family Practice (Patient-Onented Evidence that Matters (POEMs]), collection of systematic reviews from the Cochrane Library, practice guidelintsclinical prediction rules, and a Bayesias calculator with information on diagrot tic tests and physical exam manoenves In their pilot project, 7 medical sudents 
were each given a Newton computer at the beginning of their clerkship. The studentsmost frequently consulted the drug information database and the POEMs. Applications for other microcomputers, such as the Palm Pilot are also being developed (12). Their formal testing will contribute to our understanding of what to provide and how to provide it.

All of this work suggests that clini-cian, at all levels of training and expertse, want rapid access to evidence at the pont of care but can only spare seconds to get at it. We still have a long way to goin getting it to them quidkly enough.

Sharon E. Straus, $M D$ Centre for Evidence-Based Medicine Unizersity of Oxford Oxford, England, UK

\section{References}

1. Sackett DL, Rosenberg WM, Gray JA, Haynes RB, Richardson WS. Evidence based medicine: what it is and what it isn't. BM]. 1996;312:71-2.

2. Haynes RB, Sackett DL, Gray JM, Cook Df, Guyatt GFI. Transferring exidence from research into practice: 1 . The role of clinical care research evidence in clinical decisions. Evidence-Based Medicine. 1996; 1:196-7.

3. Jacobson LD, Edwards AG, Gratier SK, Butler CC. Evidence-based medicine and general practice. Br J Gen Pract. $1997 ; 47: 449-52$.

4. Davidoff $F$, Haynes B, Sackett D, Smith R. Evidence based medicine. BMJ. 1995;310: $1085-6$.

5. Sackett DL, Richardson WS, Rosenberg W, Haynes RB. Evidence-Based Medicine: How to Practice and Teach EBM. London: Churcisill Livingstone; 1997.
6. Ebell MH, Gaspar DL, Khurana S. Family physicians' preferences for computerized decision-support hardware and software. J Fam Prace, 1997;45:137-41.

7. Sackett DL, Straus SE. Finding and applying evidence during clinical rounds: the "evidence cant." JAMA. 1998;280:1336-8.

8. Straus SE, Sackett DL. Pilot test of handheld computers [Letter]. ]AMA. (In press.)

9. Helwig AI, Flym C. Using paln-top computers to inprove students' evidencebased decision making. Acad Med. 1998; 73:603-4.

10. Ebell MH, Baxry HC. InfoRetriever: rapid access to evidence-based information on a hand-heid computer. MD Comput. $1908 ; 15: 289,292-7$.

11. Ebell MH, Messimer SR, Barry HC. Putting computer based evidence in the hands of clinicians [Letter]. JAMA. 1999; 281:117:.

12. URL: www.mtco.corv/ glwoods/defaulththn. 


\section{Correction}

Strata SE. Bringing evidence to the point of care. Evid Based Med 1999;4:70-71. The author's surname should be spelled 'Sharon E Straus'.

doi:10.1136/ebm.1999.4.70corr1 